\title{
The Systemic Change Process in Education: A Conceptual Framework
}

\author{
Roberto Joseph \\ Hofstra University, United States \\ Charles M. Reigeluth \\ Indiana University, United States
}

\begin{abstract}
This paper provides a conceptual framework for a systemic change process, both to help researchers advance knowledge about how school districts can engage in paradigm change, and to help educators and policy makers understand the big picture for such change. The conceptual framework is comprised of key ideas that have emerged from the authors' experiences in facilitating change in school districts, and from a review of the educational change literature. The authors first present an argument for the need for systemic change. They then present the conceptual framework, which is comprised of six elements that are important for any systemic change process to succeed: broad stakeholder ownership, learning organization, understanding the systemic change process, evolving mindsets about education, systems view of education, and systems design. The description of each element includes suggested activities for implementation. Finally, the authors recommend that policy makers address each of the elements within the framework, and that educators and scholars explore how the interrelationships and interdependencies of the elements can lead to successful educational reform.
\end{abstract}

Keywords: Systemic Change; Educational Change; Educational Reform; Conceptual Framework; Change Process

\section{Introduction}

There is a growing recognition that, while our K-12 public education system was remarkably effective at meeting our educational needs during the industrial age, it is fundamentally inadequate for meeting our vastly different educational needs in the information age (Caine \& Caine, 1997; Duffy, Rogerson, \& Blick, 2000; Fullan, 1993; McCombs \& Whisler, 1997; Reigeluth, 1994; Schlechty, 1990).

In general, educational change can be of two basic types: piecemeal change, which entails making adjustments to the current paradigm of education, and systemic change, which entails transforming the current paradigm into a different one (Banathy, 1991, 1996; Reigeluth, 1994). Drucker (2001) refers to these as continuous change and discontinuous change, respectively. For 
example, given that people learn at different rates, our current paradigm of education teaches a group of students the same content in the same amount of time. By holding time constant, achievement is forced to vary; and by using norm-referenced testing, it is clear that this system is designed for sorting students rather than for helping all students to succeed (Reigeluth, 1994).

An alternative paradigm, one focused on learning rather than sorting, is one that allows each student to proceed to new material as soon as, but not until, the current material has been mastered. It, therefore, holds achievement constant (at a mastery level), which requires each child to be given as much time as needed to reach mastery (Reigeluth, 1994). This requires criterion-referenced testing that is used for formative as well as summative purposes. The transformation from a sorting-focused, time-based system to a learning-focused, attainmentbased system would require fundamental changes throughout all aspects of our public education systems, which is an example of what we mean by systemic change. While the term "systemic change" has different meanings to different people (see, e.g., Squire \& Reigeluth, 2000), we define it as a change of paradigm.

Given the importance of transforming our educational systems from the sorting-focused paradigm to the learning-focused paradigm, there is a strong need to advance our knowledge about how to do so. We find it helpful to think in terms of two fundamentally different knowledge bases corresponding to the process-product or means-ends distinction. The product or end of the transformation process is the new educational system, whereas the process or means is how to get to that end. The comprehensive school designs, such as Modern Red Schoolhouse and Success for All (see e.g., Stringfield, Ross, \& Smith, 1996), are examples of knowledge bases primarily about the ends, whereas the Guidance System for Transforming Education (Jenlink, Reigeluth, Carr, \& Nelson, 1996, 1998), Step Up To Excellence (Duffy, 2002, 2003), and School System Transformation Protocol (Duffy \& Reigeluth, 2008) are examples of knowledge bases about the systemic change process.

There is a strong need to advance our knowledge about the systemic change process. Toward that end, in this paper we present a conceptual framework of the systemic change process. We propose that the framework can serve as a lens through which to review important educational change efforts and school change. The framework provides a set of concepts that can be used to think about a systemic change process. It can also be used as a tool to examine the educational change literature.

\section{The Systemic Change Process: A Conceptual Framework}

In this section we present a synthesis of the major ideas that have emerged from our own experiences facilitating change in schools (see Joseph \& Reigeluth, 2005; Reigeluth \& Stinson, 2007a, 2007b, 2007c, 2007d; Richter \& Reigeluth, 2006; Watson \& Reigeluth, 2008) and from a review of the literature, including: (a) the systemic change literature, (b) case studies about educational change efforts, and (c) school change models. Throughout the article we refer to the Metropolitan School District of Decatur Township, a small school district in Indianapolis with which we have been working, as one case where we have found all the elements of the conceptual 
framework at work. We use this school district as a means to provide the reader with examples of how the framework can be used in real life.

The conceptual framework (see Figure 1) includes six major aspects that are important for any systemic change process to succeed:

- broad stakeholder ownership,

- learning organization,

- understanding the systemic change process,

- evolving mindsets about education,

- systems view of education, and

- systems design.

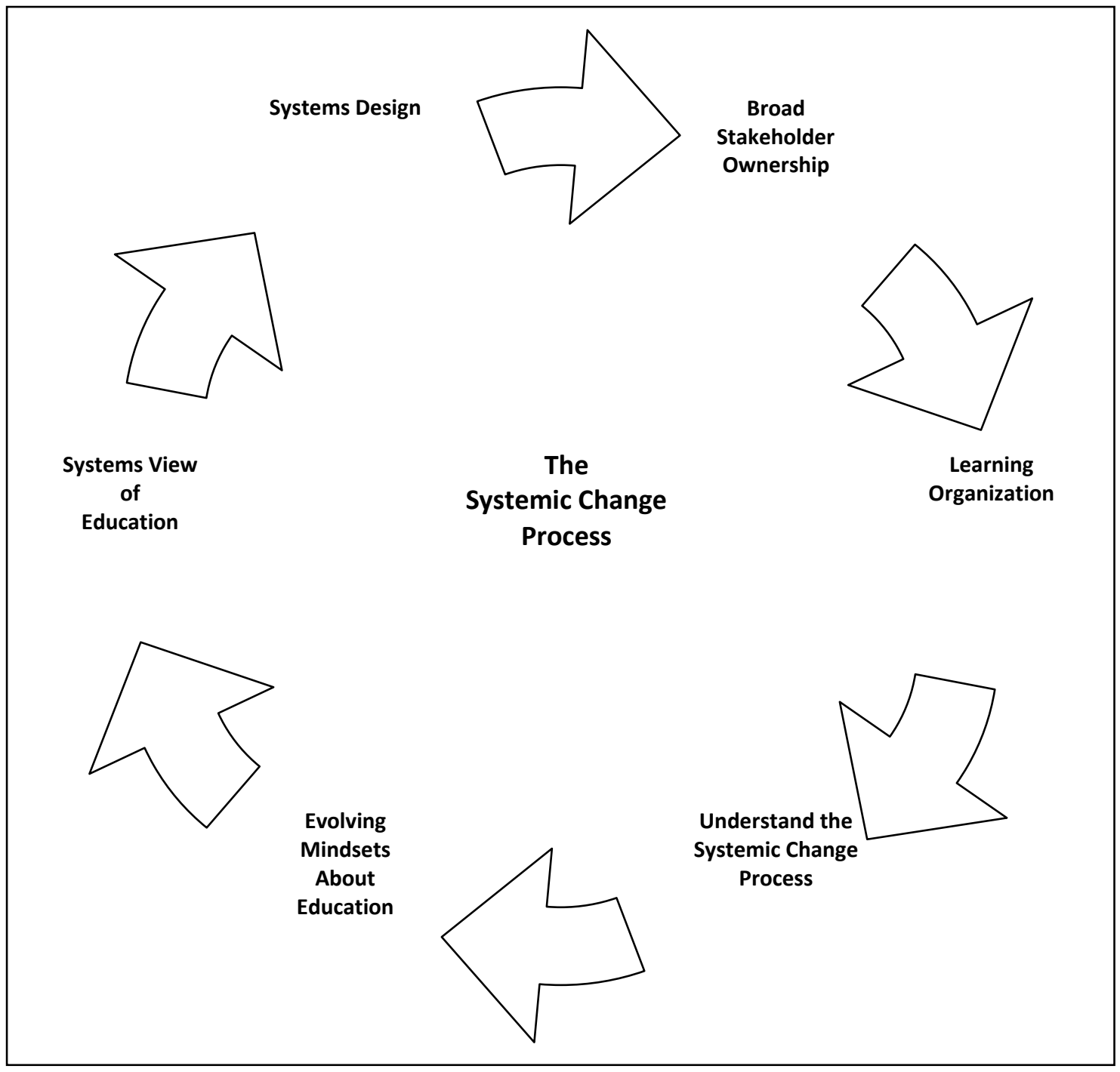

Figure 1: A Conceptual Framework of the Systemic Change Process 
These six elements overlap and are presented in a loop to represent an iterative process. The arrows indicate a recommended sequence or order for the process. It would seem logical to start with building broad stakeholder ownership. However, it is also possible to begin with developing a learning organization while building broad stakeholder ownership. Similarly, if you work in a school that already has an established learning organization, then you could immediately start with understanding the systemic change process. Following is a description of each of these six elements.

\section{Broad Stakeholder Ownership}

Broad stakeholder ownership is the fundamental bedrock upon which all other aspects of the conceptual framework of the systemic change process are built. Without broad stakeholder ownership, the other elements of the framework lose their meaning and sense of purpose.

Educational stakeholders are the people in a school community (e.g., parents, teachers, students, civil servants, clergy) that have a vested interest, or "stake," in the school system in their neighborhood. While it may seem obvious why school personnel, parents, and students should be vested in the educational system, what is not so obvious is why individuals who may not have children or work within the system should be vested. A major reason is that the welfare of every stakeholder in a democracy depends to some extent on the welfare of all other members of that community, and therefore, they should be interested in ensuring that every child be provided with the best educational opportunities (Clinton, 1996; Goodlad, 2002) in order to continue the improvement of their community. The education of our children has a direct influence on the quality of government, level of crime, and amount of retirement support that all members of our society can expect. These are a few of the reasons why all members of a community should be vested in their public educational system. Without this vested interest by a broad and diverse base of stakeholders, the democratic goals of a society are likely to become unattainable.

Recently, with the sense of urgency to change and improve public schools in the United States and other countries, parents have been asked to join school-based management (SBM) teams. SBM teams give parents the opportunity to get involved in important matters and to begin to take ownership by being a part of the school decision-making process (Fine, 1993). In his book, Parental Involvement and the Political Principle, Sarason (1995) characterized "the political principle" with these words: "When you are going to be affected, directly or indirectly, by a decision, you should stand in some relationship to the decision making process" (p.7). Asking parents to be a part of decision-making in a change process is clearly a step toward helping parents not only to get involved, but also to take ownership of the change process.

For example, in the Metropolitan School District of Decatur Township, parents and other community members were members of the district-wide "Leadership Team," which was empowered by the school board and superintendent to lead their systemic change process (Reigeluth \& Stinson, 2007c). These community members had equal voice with the other stakeholders on the team: teachers, administrators, non-teaching staff, and school board members. 
However, the dialogue surrounding involvement needs to shift from seeking only parental involvement to seeking and developing broad stakeholder ownership (Fine, 1993). This was accomplished in the Decatur Township school district by developing the capacity of all members of the team to make decisions about the change process as well as about the desired changes for the school district (Reigeluth \& Stinson, 2007a). All Leadership Team members were strongly encouraged to share their thinking with others in their stakeholder groups and to bring forward ideas of those others.

Bringing stakeholders together who have diverse backgrounds, experiences and opinions strengthens the change process. If voices of stakeholders are left out, particularly the voices of those who have been historically marginalized, then the change process is weakened and is more susceptible to adverse reactions from these very same stakeholders.

When it comes to engaging parents and other stakeholders in a systemic change process, Banathy (1996) expands Sarason's notion of "the political principle" with this profound statement:

When it comes to the design of social and societal systems of all kinds, it is the users, the people in the system, who are the experts. Nobody has the right to design social systems for someone else. It is unethical to design social systems for someone else. Design cannot be legislated, it should not be bought from the expert, and it should not be copied from the design of others. If the privilege of and responsibility for design is "given away," others will take charge of designing our lives and our systems. They will shape our future. (p. 228)

Banathy transcends "the political principle" based on decision making, to offer a political principle based on designing, and seizing ownership of designing, a new educational system.

In order for a broad range of stakeholders to feel a sense of ownership in an educational change process, their roles would need to fundamentally change. They not only would need to be involved and help make decisions, but would also need to become creators, designers and visionaries of a new and fundamentally different educational system. As in the Decatur Township, stakeholders will need to evolve their mindsets, develop a systems view, and understand the systemic change process (all elements of our conceptual framework described below) to be able to begin the process of designing a new educational system (Reigeluth \& Stinson, 2007b).

Hence, new types of relationships and opportunities must be created that would allow a broad range of stakeholders to come together to envision, design and implement their ideal educational system. Only then can we say that stakeholders, including parents, have total ownership over their change process and their educational system, because they would have designed it. A key ingredient for a systemic change process in education is broad stakeholder ownership.

\section{Suggested Activities to Develop Broad Stakeholder Ownership}

A school district could build broad stakeholder ownership through a number of methods. 
- Form a leadership team, comprised of diverse members from the district and larger community, whose purpose is to develop the district's framework of mission, vision and ideal beliefs.

- Hold community forums in the schools, civic organizations, and places of worship to share, discuss and improve the framework.

- Form design teams in each school to create ideal designs of what they want their new school to be like. Also form input groups comprised of all interested stakeholders who are not on the design team for their school. Each input group would meet regularly with two members of the design team to find out how their thinking has evolved and to provide input on the changes the design team envisions.

\section{Learning Organization}

Many researchers have found that developing a learning organization is an important aspect to pursuing the systemic change process (Darling-Hammond, 1996; DuFour \& Eaker, 1998; Fullan, 1993, 2001; Louis \& Kruse, 1995; Newmann, Wehlage, \& Wisconsin Center for Education Research. Center on Organization and Restructuring of Schools., 1995; Senge, 1990). DiBella and Nevis (1998) state, "It is important to differentiate between the similar and related ideas of 'organizational learning' and the 'learning organization' because they are often used interchangeably" (p. 6). They suggest that

The learning organization is a systems-level concept with particular characteristics or a metaphor for the ideal organization... In contrast, "organizational learning" is a term used to describe certain types of activities or processes that may occur at any one of several levels of analysis [individual, team and organization] or as part of an organizational change process. Thus it is something that takes place in all organizations, whereas the learning organization is a particular type or form of organization in and of itself. (p. 6)

This distinction seems to suggest that the learning organization is what an organization strives to become (product); it is an ideal vision of an organization. This distinction also suggests that organizations must develop and implement organizational learning activities, strategies, and processes in order to become a learning organization. According to Mulford (1998):

Organizational learning largely focuses on developing common understandings, honesty, and trust through dialogue, sharing, and managing the inevitable conflict involved. These learning processes are then employed to make links to the outside, to examine current practice critically, to develop shared values as well as a vision for the school. The processes, the content (or identified changes), and shared values are employed to actually make the changes that have been identified, including a commitment and ability to repeat the stages, that is, to continuously learn and improve. (p. 619)

According to Senge (1990) the basic meaning of a learning organization is

... an organization that is continually expanding its capacity to create its future. For such an organization, it is not enough merely to survive. "Survival learning" or what is more often 
termed "adaptive learning" is important-indeed it is necessary. But for a learning organization, "adaptive learning" must be joined by "generative learning," learning that enhances our capacity to create. (p. 14)

Thirty years ago Argyris and Schon (1978) argued that organizational learning was critical to an organization's survival. They defined organizational learning as "an organization's capacity for conscious transformation of its own theory of action, and to individuals' ability to appreciate and transform the learning systems in which they live" (p. 331). Argyris and Schon (1978) defined an organization's theory of action as its norms, strategies, and assumptions. According to them:

... organizational theories of action need not be explicit. Indeed, formal corporate documents such as organizational charts, policy statements, and job descriptions often reflect a theory of action (the espoused theory) which conflicts with the organization's theory-in-use (the theory of action constructed from observation of actual behavior)-and the theory-in-use is often tacit. (p. 331 )

Argyris and Schon (1978) suggested that "for systems theorists, organizational learning consists of the self-regulating process of error-detection and error-correction itself, whether or not maintenance of the organizational steady state is mediated by the self-conscious efforts of individual members of the organization" (p. 326). Argyris and Schon (1978) used the term singleloop learning to refer to the self-regulating process of error detection and error correction. They stated that during single-loop learning "members of the organization respond to changes in the internal and external environments of the organization by detecting errors which they then correct so as to maintain the central features of organizational theory-in-use" (p. 18). In organizational single-loop learning, the criterion for success is effectiveness. According to Morgan (1997):

... many organizations have become proficient at single-loop learning, developing an ability to scan the environment, set objectives, and monitor general performance of the system in relation to these objectives. This basic skill is often institutionalized in the form of information systems designed to keep the organization "on course." (p. 88)

Single-loop learning by itself does not challenge or question an organization's theory of action (i.e., organizational norms, strategies, and assumptions). Argyris and Schon (1978) argued that organizations need to learn to build the capacity to challenge their own theory of action. They called this type of learning double-loop learning, which they defined as "those sorts of organizational inquiry which resolve incompatible organizational norms by setting new priorities and weightings of norms, or by restructuring the norms themselves together with associated strategies and assumptions" (p. 24).

According to Morgan (1997) double-loop learning is much more difficult for an organization to achieve. He states:

... the ability to achieve proficiency at double-loop learning often proves more elusive. Although some organizations have been successful in institutionalizing systems that review and challenge basic paradigms and operating norms, many fail to do so. This failure 
is especially true of bureaucratized organizations, whose fundamental organizing principles often operate in a way that actually obstructs the learning process. (p. 88)

Peter Senge (1990) identifies seven organizational learning disabilities that can hinder the organization from becoming a learning organization:

1. I AM MY POSITION: When people in organizations focus only on their position, they have little sense of responsibility for the results produced when all positions interact. (p. 19)

2. THE ENEMY IS OUT THERE: There is in each of us a propensity to find someone or something outside ourselves to blame when things go wrong. (p. 19)

3. THE ILLUSION OF TAKING CHARGE: All too often, "proactiveness" is reactiveness in disguise. If we simply become more aggressive fighting the "enemy out there," we are reacting-regardless of what we call it. True proactiveness comes from seeing how we contribute to our own problems. (p. 21)

4. THE FIXATION ON EVENTS: Generative learning cannot be sustained in an organization if people's thinking is dominated by short-term events. If we focus on events, the best we can ever do is predict an event before it happens so that we can react optimally. But we cannot learn to create. (p. 22)

5. THE PARABLE OF THE BOILED FROG: Learning to see slow, gradual processes requires slowing down our frenetic pace and paying attention to the subtle as well as the dramatic. (p. 23)

6. THE DELUSION OF LEARNING FROM EXPERIENCE: Herein lies the core learning dilemma that confronts organizations: we learn best from experience but we never directly experience the consequences of many of our most important decisions. (p. 23)

7. THE MYTH OF THE MANAGEMENT TEAM: All too often, teams in business tend to spend their time fighting for turf, avoiding anything that will make them look bad personally, and pretending that everyone is behind the team's collective strategymaintaining the appearance of a cohesive team. (p. 24)

Senge (1990) believes that "the five disciplines of the learning organization [Personal Mastery, Shared Vision, Team Learning, Mental Model, and Systems Thinking] ... can act as antidotes to these learning disabilities. But first, we must see the disabilities more clearly-for they are often lost amid the bluster of day-to-day events" (p. 26).

Identifying learning disabilities within an organization requires that an organization learns how to learn. Argyris and Schon (1978) borrowed the term deutero-learning from Gregory Bateson to explain their notion of learning how to learn. They stated that:

When an organization engages in deutero-learning, its members learn, too, about previous contexts for learning. They reflect on and inquire into previous episodes of organizational learning, or failure to learn. They discover what they did that facilitated or inhibited learning, they invent new strategies for learning, they produce these strategies, and they evaluate and generalize what they have produced. The results become encoded in individual images and maps and are reflected in organizational learning practice. (p. 27) 
Argyris and Schon (1978) stated that "the quest for organizational learning capacity must take the form of deutero-learning; most particularly about the interactions between the organization's behavioral world and its ability to learn" (p. 29).

Argyris and Schon (1978) argued that without individual learning there is no organizational learning; however, they also argued that individual learning by itself is insufficient for organizational learning. They stated:

We can think of organizational learning as a process mediated by the collaborative inquiry of individual members. In their capacity as agents of organizational learning, individuals restructure the continually changing artifact called organizational theory-in-use. Their work as learning agents is unfinished until the results of their inquiry-their discoveries, inventions, and evaluations-are recorded in the media of organizational memory, the images and maps which encode organizational theory-in-use. (p. 20)

Developing a learning organization is the element of the conceptual framework that binds all the other elements together. It is perhaps the most critical element of the systemic change process, and therefore much time and care should be taken to ensure the development of a healthy learning organization. In Decatur the Leadership Team of about 25-30 leaders from all stakeholder groups has continually strived to be a learning organization by learning about Senge's five disciplines of a learning organization, discussing readings together, engaging in double-loop learning exercises, and engaging in deutero-learning (Reigeluth \& Stinson, 2007c). However, the Leadership Team has found that it is not easy to maintain a focus on double-loop learning, nor even on deutero-learning.

\section{Suggested Activities to Develop a Learning Organization}

A school district could use several methods to build a learning organization.

- During large community forums help individuals to form into smaller discussion groups. For each group, put a high priority on double-loop learning.

- Hold retreats and offer workshops periodically to help individuals engage in doubleloop learning and deutero-learning.

- Use emerging technologies (i.e. blogs, wikis, podcasts) to facilitate communication, exchange ideas, and share resources about double-loop learning.

- Encourage and reward critical thinking about the way things are done in the organization.

\section{Understand the Systemic Change Process}

In order to build a sense of stakeholder ownership and to build a learning organization, stakeholders should have a deep understanding of the systemic change process (or paradigm change process). This understanding is the bridge to educational transformation. Communication and dialogue are important parts of the systemic change process. They are vehicles for bringing a diverse group of stakeholders together for a journey toward understanding and appreciating 
diverse stakeholders' values, beliefs and opinions (Jenlink, 1995). Communication and dialogue among educational stakeholders fosters the recognition of system relationships in society (i.e., among family, education, and community). The journey to this deep understanding requires first, an understanding that the ultimate goal of any systemic change process is to invent an educational paradigm where all teachers succeed at helping all students succeed.

Second, it is important to understand that to invent a fundamentally different educational system will require helping people to evolve their mindsets about education (Caine \& Caine, 1997; Jenlink, 1995). Mindset change is the essence of a systemic change process.

Third, it is also important to understand that during a systemic change process much of the time is spent in small process teams (five to six stakeholders) led by a process facilitator (Caine \& Caine, 1997; Jenlink, et al., 1998). The major work of the process teams is to: (a) develop a deep understanding of the systemic/paradigm change process, (b) evolve their own mindsets and help the school community members to evolve their mindsets about education through dialogue, and (c) envision, design, and implement an ideal educational system with active involvement of as many stakeholders as possible.

Fourth, we must understand that it is only through dialogue within process groups that we can begin to help stakeholders evolve their mindsets about education. According to Bohm (1996):

The object of a dialogue is not to analyze things, or to win an argument, or to exchange opinions. Rather, it is to suspend your opinions and to look at the opinions - to listen to everybody's opinions, to suspend them, and to see what all that means. (p. 26)

Lastly, understanding the systemic change process requires an understanding of each of the elements outlined in this conceptual framework.

In Decatur, both the small Core Team and the larger Leadership Team into which it expanded spent many hours learning together about the systemic change process (Reigeluth \& Stinson, 2007c). Eventually, the Leadership Team formed a committee to study the systemic change process and tailor it to the Decatur community and school system. This committee has created the "Decatur Systemic Reinvention Process" based on the School System Transformation Protocol developed by Duffy and Reigeluth (2008).

\section{Suggested Activities to Develop an Understanding of the Systemic Change Process}

A school district could use a variety of methods to help all stakeholders understand the systemic change process.

- A good place to start is with the conceptual framework presented in this article. It can be used as a guide to structure workshops, readings, and discussion groups. 
- Other readings to use in workshops and discussion groups include Senge (2000), Hammer and Champy (2001), McCombs and Whisler (1997), Caine and Caine (1997), Duffy (2002), Schlechty (2005), and Reigeluth (Reigeluth, 1993, 2006, 2008).

\section{Evolve Mindsets}

There is a socio-cultural and ideological vision that is deeply engrained in our minds for what we call school. When we think of school, or "the grammar of schooling" (Tyack \& Cuban, 1995), we think of classrooms, each with a teacher lecturing to a group of students; we think of textbooks, a black board, chalk, the principal; we think of having to pass standardized exams; we think of grade levels, courses, and subject areas in a chunked curriculum; we think of grades and credits (i.e., the Carnegie Unit); and we think of moving on to the next grade level at the beginning of the next school year. We have been acculturated to view schools in a certain way, and until we can evolve our mental models of what we believe are "real schools" (Tyack \& Cuban, 1995), we will not achieve fundamental changes in education (Senge, 2000).

One can argue that helping stakeholders to evolve their mindsets and mental models about education is perhaps the most important aspect of a systemic change process. The use of the terms mindset, worldview, and paradigm are all roughly synonymous with the term mental model. Senge (1990) explains:

Mental models are deeply ingrained assumptions, generalizations or even pictures or images that influence how we understand the world and how we take action. Very often we are not consciously aware of our mental models or the effects they have on our behavior. (p. 8)

The term mindset is preferred here because the term itself defines the major problem we are experiencing in education today. As a society our minds are set in an obsolete view of what and how a "real school" is supposed to look and function (Tyack \& Cuban, 1995). The culture of schooling is deeply ingrained and set in our minds. When one's mind is set, it is nearly impossible to change one's disposition. Yet it is this nearly impossible task of evolving mindsets or reculturing (Fullan, 1993; Fullan \& Stiegelbauer, 1991) that is the key to successfully transforming an educational system to the new paradigm. Whatever term is used, researchers are beginning to agree that the process of systemic change is based on helping people to change and evolve their mindsets about education (Caine \& Caine, 1997; Jenlink, 1995).

In the Decatur Township, most of the learning process that the Core Team and Leadership Team have undergone has focused on helping members to evolve their mindsets about education (Reigeluth \& Stinson, 2007d). This has been accomplished primarily through readings and smallgroup dialogue, and the Indiana University facilitators recently developed a set of videos for use in workshops for all stakeholders at the school level of the system. 


\section{Suggested Activities to Help Stakeholders Evolve their Mindset about Education}

A school district could use the following method to help all stakeholders to evolve their mindsets about education.

- Make presentations followed by dialogue groups that focus on the differences between a standardized, time-based, sorting-focused system and a customized, attainment-based, learning-focused system - for all team members in team meetings and for all other interested stakeholders in community forums.

\section{Systems View}

For years educators have been trying to analyze why their schools are failing by observing the classroom, talking with teachers, parents, and principals, and identifying various school indicators of improvement (test scores, grades, attendance rates, parent involvement, suspensions, etc.). These attempts can be characterized as piecemeal methods of analysis that have yet to help educators and researchers create fundamental changes in education. In the following passage Capra (1982) explains how isolating elements of a system in order to analyze it will in effect destroy our ability to develop a holistic view of the system:

Systemic properties are destroyed when a system is dissected, either physically or theoretically, into isolated elements. Although we can discern individual parts in any system, the nature of the whole is always different from the mere sum of its parts. (p. 267)

Educational stakeholders need to develop a systemic view of educational systems and an understanding of the activity (or dynamics) of systems in order to undertake serious systemic change efforts in education. According to Capra (1982), "the activity of systems involves a process known as transaction-the simultaneous and mutually interdependent interaction between multiple components" (p. 267). Developing a systems view requires that we begin to view "the world in terms of relationships and integration" (Capra, 1982, p. 266). Banathy (1992) provides three different explanations for helping us to understand the concept of a "systems view" and its importance to the systemic change process:

- "The systems view helps us to understand the true nature of education as a complex, open, and dynamic human activity system that operates in ever-changing multiple environments and interacts with a variety of societal systems" (p. 17).

- "The systems view is a certain way of looking at ourselves, at the environments we live in, at the systems that surround us, and at those we are a part of" (p. 15).

- "The systems view is a way of thinking, it is a world view we can possess. And there are ways by which it can be developed" (p. 16).

The absence of a systems view can lead to unexpected consequences when educational stakeholders are not aware of the interrelationships that exist within educational systems. It is likely that developing a systems view will help people to evolve their mindsets about education. 
In the following subsections, two methods will be presented for helping people to develop a systems view of education: 1 ) the use of systems models, and 2) the use of metaphors. The first section describes Banathy's (1991) systems models (systems-environment, functions/structure, and process models), and the second section outlines Morgan's (1997) metaphors for viewing organizations. The second section also offers examples of the use of metaphors in the context of education.

\section{Systems Models}

Banathy suggests two stages in helping people to develop a systems view of education. The first stage requires that we observe and study various systems and their behavior, in order to identify the common concepts. The first stage also requires that we probe to find relationships among the concepts in order to establish principles. For example, the concept, "community of practice," may be found to have a certain impact on concepts like "teacher motivation" and "student achievement." According to Banathy (1992), "a system principle emerges from an interaction/integration of related concepts" (p. 16). To complete the first stage, we must find relationships among the principles, and these related principles will form the basis for the systems models that we create.

The second stage requires that we internalize the systems models that we create and apply them to a real-life situation that is meaningful to us. One way to apply them is to use them to analyze a particular system. Banathy (1992) has developed three systems models, which he refers to as lenses, "that can be used to look at an educational activity system and understand, describe, and analyze it as an open, dynamic, and complex social system" (p. 21).

Systems-Environment Model, also called the "bird's-eye-view" lens, allows us to describe an educational system within the context of its larger environment (e.g., a school system's community and larger society). The bird's-eye-view allows us to see the existing or future relationships, interactions, and patterns of interdependence the educational system has with its larger environment.

Functions/Structure Model, also called the "still picture" lens, allows us to view the state of the educational system at a given point in time. Think of a school system as constantly moving and changing. Now imagine stopping the motion of the school system to take a close look at the goals and purposes of the system. This lens allows us to examine what functions and structures are in place within the school system that serve to carry out the goals and purposes of the system at that point in time.

Process Model, also called the "motion picture" lens, allows us to examine the behavior of the school system over time (in the context of the community and larger society). The process lens helps us to understand how the school system receives, assesses and processes input, how the system transforms input to meet the purposes and goals of the system, and how the system processes and assesses the output. Banathy's process model requires a thorough understanding of system dynamics. Forrester (1999), a pioneer of the field of system dynamics, provides a definition: 
System dynamics deals with how things change through time which covers most of what most people find important. System dynamics involves interpreting real life systems into computer simulation models [STELLA] that allow one to see how the structure and decision-making policies in a system create its behavior. (p. 1)

Forrester argues that system dynamics is the foundation under systems thinking. Teaching and learning about system dynamics by creating computer simulations of systems models can help people to visualize and think effectively about systems (Forrester, 1999).

Banathy emphases the importance of using all three lenses or models and that no one model can give a complete systems view of a complex school system in the context of its community and larger society. Educators can learn to acquire a systems view of education by observing various school systems and identifying common concepts from which related principles can emerge, and in turn systems models can be created from these principles.

The Leadership Team in the Decatur Township devoted considerable time to readings on systems thinking and applying what they learned to their school system (Reigeluth \& Stinson, 2007c). Their experience demonstrates that it is only when we internalize and apply the systems models to our own situations that we can truly expect to develop a systems view of education.

\section{Metaphors}

In addition to systems models, metaphors are important tools in helping people to see and understand complex systems and to develop a systems view of education. According to Morgan (1997), "we use metaphor whenever we attempt to understand one element of experience in terms of another" (p. 4). Metaphors can also be useful in helping people to evolve their thinking and mindsets about education. Morgan (1997) presents eight metaphors as models or lenses for viewing, describing, analyzing and understanding organizations systemically:

1. organizations as machines

2. organizations as organisms

3. organizations as brains

4. organizations as cultures

5. organizations as political systems

6. organizations as psychic prisons

7. organizations as flux and transformation

8. organizations as instruments of domination.

No one metaphor can give a total view of the system. Therefore, Morgan recommends using a dominant metaphor and other supporting metaphors to give a more accurate depiction of the organization. For example, according to Morgan, using the organizations as political systems metaphor as the dominant metaphor, "we can analyze organizational politics in a systematic way by focusing on relations between interests, conflict, and power" (p. 160). In analyzing the interests of the stakeholders in the school community, it is important to frame the dialogue around their 
goals, values, desires, and expectations (Morgan, 1997). According to Morgan (1997), when the interests of various stakeholders collide, you can expect there will be conflict. Those in power are the ones to resolve the conflicts (Morgan 1997). In school systems, school boards are given the power, by the state, to resolve conflicts that arise within their school districts. The school board makes the final decisions on critical issues within the district.

One can easily use the "psychic prisons" metaphor as a supporting metaphor for the political systems metaphor. For example, in addition to being political, the school system is designed in such a way that it does not promote constructive communication amongst the various stakeholder groups. It is not common to see a superintendent, school board, teachers, and community members coming together in a collaborative way to work towards a shared vision. Instead, what exists is a system of "psychic prisons", whereby interests, visions, and ideologies are not shared with the entire school community. It is precisely these psychic prisons that form the basic structure of political systems. Stakeholder groups exist in many different secluded realities or psychic prisons, and as such it is difficult to get these groups to suspend and free themselves from their realities in order to experience a new, shared reality.

Metaphors can be used as lenses, theories, or systems models in order to help stakeholders develop a systems view of their educational system. Morgan (1997) states:

In recognizing theory as metaphor, we quickly appreciate that no single theory will ever give us a perfect or all-purpose point of view. We realize that the challenge is to become skilled in the art of using metaphor: to find fresh ways of seeing, understanding, and shaping the situations that we want to organize and manage. (p. 5)

Helping educational stakeholders to acquire a systems view of education by helping them work with systems models and organizational metaphors will facilitate the major work of the systemic change process: systems design.

\section{Suggested Activities to Develop a Systems View}

A school district could help all stakeholders to develop a systems view of education in a variety of ways.

- Though workshops, readings, and dialogue groups, leadership and design team members can analyze their own school system from a systems view.

- You can use Banathy's three lenses to describe a classroom as a system, or a professional development program as a system, or a whole school as a system, or to describe the district's transportation system, and thereby gradually build up to an analysis of the entire school district as a system.

- Using Senge's "iceberg," you can identify important events that occur in the district, then identify patterns of events, then identify structures that underlie those patterns, and finally identify the mental models that underlie those structures.

- You can use Morgan's eight "Images of Organizations" as metaphors to analyze your educational system. 
- Also, you can hold regular community forums that help all stakeholders to understand their school system from a systems view perspective, using the techniques mentioned above.

\section{Systems Design}

The systemic change process must be a systems design process (Banathy, 1991). According to Banathy (1991), "Systems design in the context of any human system is a future-creating activity. People engage in it based on their vision of what their system should be. They are a think futureact now' kind of people" (p.165). The process of systems design should take stakeholders on a journey from the current, obsolete educational system to an ideal design of their educational system. Banathy (1996) advises that the design journey begin by engaging in a dialogue about why we want to engage in design. He calls this dialogue the "genesis of design" and outlines five major design processes that should follow the genesis of design (Banathy, 1996):

- Transcending the existing system and leaving it behind.

- Envisioning an image of the system that we wish to create.

- Designing the system, which, when implemented, transforms the existing state to the desired future state.

- Presenting/displaying the model(s) of the system we design.

- Planning for the implementation of the design. (p. 61)

However, prior to actually engaging in a systems design process, Banathy (1991) recommends that stakeholders initiate the process of 'Getting Ready for Design,' which entails:

1) Understand Systems Design

2) Develop Capability and Competence in Design

3) Develop Organizational Capacity for Design

4) Generate Willingness in the Community to Support the Design Effort

5) Prepare a plan for the design inquiry (p. 165)

Banathy (1991) places great value on systems design, and he believes that "systems design is most successful, it is most viable and productive, and commitments to implementing the design are most binding, when it is directed by the users of the future system rather than by outside experts" (p. 166). One way to help stakeholders, the users of the system, build their sense of ownership of the systemic change process, is to help them to "Get Ready for Design."

Systems design requires a thorough understanding of a systems view of education in general and of system dynamics in particular (see earlier description).

Both Ackoff $(1981)$ and Banathy $(1991,1996)$ recommend an "ideal design" approach to systems design. According to Banathy (1996), "in the ideal systems design approach, the target is always the ideal. The target cannot ever be less than ideal... Design is a journey toward the ideal." (p. 194). Jenlink (1995) states that "systems design is an inseparable part of systemic change; the ideal is in the process of creating, not in the content of the process" (p. 43). For any systemic 
change process to succeed, it should seek to envision and create an ideal educational system using a systems design approach.

\section{Suggested Activities to Develop an Understanding of Systems Design}

Given an understanding of the systemic change process, a school district can use several methods to help all stakeholders use a systems design approach to systemic change.

- One option is to read and discuss the systems design process models of Bela Banathy (1991), Frank Duffy (2002; 2003; Duffy, Rogerson \& Blick, 2000), Jenlink, Reigeluth, Carr and Nelson (1996; 1998), and Duffy and Reigeluth (2008). Major points include:

- continuously helping stakeholders to transcend their images of school,

0 thinking in the ideal about a new system designed from scratch, and

- taking a spiral approach from fuzzy vision to functions, subsystems, and a detailed model of their new system.

\section{Conclusion}

The conceptual framework presented here is a tool for scholars, educators, and policy makers. It identifies important areas within which scholars can conduct research to develop (a) guidance for the systemic change process and (b) theories to explain the causal phenomena involved in systemic change. It is a framework to help educators understand how to create and sustain a successful systemic change process.

Educators who wish to bring about a fundamental change from a standardized, time-based, sorting-focused system to a customized, attainment-based, learning-focused system should understand the need to create mechanisms for carrying out all six functions in the framework, for each depends upon all the others. Specific activities were recommended for carrying out each of the six functions.

Finally, the conceptual framework provides policy makers with an understanding of the kinds of functions and activities that they need to support for systemic change to succeed.

There is a rich and growing body of literature about each of the six elements that make up the conceptual framework. What has been lacking is an understanding of how these elements are interrelated and interdependent, with the consequence that systemic change efforts must pay attention to all of them, scholars must explore those interrelationships and interdependencies, and policy makers must address all of them for our educational systems to successfully transform themselves to the much-needed learner-centered paradigm of education. We also encourage scholars and change agents to explore ways of improving the usefulness of this framework. 


\section{References}

Akoff, R. L. (1981). Creating the Corporate Future. New York: John Wiley \& Sons.

Argyris, C., \& Schön, D. A. (1978). Organizational learning: A theory of action perspective. Reading, MA: Addison-Wesley Pub. Co.

Banathy, B. H. (1991). Systems design of education: A journey to create the future. Englewood Cliffs, N.J.: Educational Technology Publications.

Banathy, B. H. (1992). A systems view of education: Concepts and principles for effective practice. Englewood Cliffs, N.J.: Educational Technology Publications.

Banathy, B. H. (1996). Designing social systems in a changing world. New York: Plenum Press.

Bohm, D. (1996). On dialogue. New Fetter Lane, London: Routledge.

Caine, R. N., \& Caine, G. (1997). Education on the edge of possibility. Alexandria, VA: ASCD.

Capra, F. (1982). The turning point: Science, society, and the rising culture. New York: Simon and Schuster.

Clinton, H. R. (1996). It takes a village and other lessons children teach us. New York: Simon \& Schuster.

Darling-Hammond, L. (1996). What matters most: A competent teacher for every child. Phi Delta Kappan, 78(3), 193-200.

DiBella, A. J., \& Nevis, E. C. (1998). How organizations learn: An integrated strategy for building learning capability. San Francisco: Jossey-Bass.

Drucker, P. F. (2001). The essential Drucker: Selections from the management works of Peter F. Drucker (1st ed.). New York: HarperBusiness.

Duffy, F. M. (2002). Step-Up-To-Excellence: An innovative approach to managing and rewarding performance in school systems. Lanham, MD: Scarecrow Education.

Duffy, F. M. (2003). Courage, passion and vision: A guide to leading systemic school improvement. Lanham, MD: Scarecrow Education and the American Association of School Administrators.

Duffy, F. M., \& Reigeluth, C. M. (2008). The school system transformation (SST) protocol. Educational Technology, 48(4), 41-49.

Duffy, F. M., Rogerson, L. G., \& Blick, C. (2000). Redesigning America's schools: A systems approach to improvement. Norwood, Mass.: Christopher-Gordon Publishers.

DuFour, R., \& Eaker, R. E. (1998). Professional learning communities at work: best practices for enhancing student achievement. Bloomington, Ind. Alexandria, Va.: National Education Service; ASCD.

Fine, M. (1993). Parent involvement - reflections on parents, power, and urban public schools. Teachers College Record, 94(4), 682-710.

Forrester, J. W. (1999). Systems dynamics: The foundation under systems thinking. Retrieved October 13, 2002, from http://sysdyn.mit.edu/sdep/papers/D-4828.html 
Fullan, M. (1993). Change forces: Probing the depth of educational reform. London ; New York: Falmer Press.

Fullan, M. (2001). Leading in a culture of change. San Francisco: Jossey-Bass.

Fullan, M., \& Stiegelbauer, S. M. (1991). The new meaning of educational change (2nd ed.). New York, NY: Ontario Institute for Studies in Education: Teachers College Press Teachers College Columbia University.

Goodlad, J. I. (2002). Kudzu, rabbits, and school reform. Phi Delta Kappan, 84(1), 16-23.

Hammer, M., \& Champy, J. (2001). Reengineering the corporation: A manifesto for business revolution. New York: HarperBusiness.

Jenlink, P. M. (1995). Systemic change: Touchstones for the future school. Arlington Heights, Illinois: IRI/Skylight Training and Publishing, Inc.

Jenlink, P. M., Reigeluth, C. M., Carr, A. A., \& Nelson, L. M. (1996). An expedition for change. Tech Trends, 21-30.

Jenlink, P. M., Reigeluth, C. M., Carr, A. A., \& Nelson, L. M. (1998). Guidelines for facilitating systemic change in school districts. Systems Research and Behavioral Science, 15(3), 217233.

Joseph, R., \& Reigeluth, C. M. (2005). Formative research on an early stage of the systemic change process in a small urban school system. British Journal of Educational Technology, 36(6), 937-956.

Louis, K. S., \& Kruse, S. D. (1995). Professionalism and community: perspectives on reforming urban schools. Thousand Oaks, Calif.: Corwin Press.

McCombs, B., \& Whisler, J. S. (1997). The learner-centered classroom and school: Strategies for increasing student motivation and achievement. San Francisco: Jossey-Bass Publishers.

Morgan, G. (1997). Images of Organization (2nd ed.). Thousand Oaks, CA: Sage Publications Inc.

Mulford, W. R. (1998). Organizational Learning and Educational Change. In A. Hargreaves, M. Fullan \& D. Hopkins (Eds.), International Handbook of Educational Change (pp. 616-641). Norwell: Kluwer Academic Publishers.

Newmann, F. M., Wehlage, G., \& Wisconsin Center for Education Research. Center on Organization and Restructuring of Schools. (1995). Successful school restructuring: a report to the public and educators by the Center on Organization and Restructuring of Schools. Madison, WI: The Center : distributed jointly by the American Federation of Teachers Association for Supervision and Curriculum Development National Association of Elementray School Principals The National Association of Secondary School Principals.

Reigeluth, C. M. (1993). Principles of educational systems design. International Journal of Educational Research, 19(2), 117-131.

Reigeluth, C. M. (1994). The imperative for systemic change. In C. M. Reigeluth \& R. J. Garfinkle (Eds.), Systemic change in education (pp. 3-11). Englewood Cliffs, NJ: Educational Technology Publications. 
Reigeluth, C. M. (2006). A leveraged emergent approach to systemic transformation. TechTrends, $50(2), 46-47$

Reigeluth, C. M. (2008). Chaos theory and the sciences of complexity: Foundations for transforming education. In B. Despres (Ed.), Systems Thinkers in Action: A Field Guide for Effective Change Leadership in Education. New York: Rowman \& Littlefield.

Reigeluth, C. M., \& Stinson, D. (2007a). The Decatur story: Reinvention of a school corporation Collaboration: Developing partners in education. The Indiana School Boards Association Journal, 53(3), 13-15.

Reigeluth, C. M., \& Stinson, D. (2007b). The Decatur story: Reinvention of a school corporation Culture and climate: The personality of school governance. The Indiana School Boards Association Journal, 53(4), 11-13.

Reigeluth, C. M., \& Stinson, D. (2007c). The Decatur story: Reinvention of a school corporation Leadership and empowerment in Decatur's school transformation. The Indiana School Boards Association Journal, 53(2), 13-15.

Reigeluth, C. M., \& Stinson, D. (2007d). The Decatur story: Reinvention of a School Corporation Mission and values for Decatur's school transformation. The Indiana School Boards Association Journal, 53(1), 17-19.

Richter, K. B., \& Reigeluth, C. M. (2006). A systemic change experience in Decatur Township. Tech Trends, 50(2), 35-36, 50(2), 35-36.

Sarason, S. B. (1995). Parental involvement and the political principle: Why the existing governance structure of schools should be abolished (1st ed.). San Francisco: Jossey-Bass Publishers.

Schlechty, P. C. (1990). Schools for the twenty-first century: Leadership imperatives for educational reform (1st ed.). San Francisco: Jossey-Bass Publishers.

Schlechty, P. C. (2005). Creating great schools: Six critical systems at the heart of educational innovation. San Francisco: Jossey-Bass.

Senge, P. M. (1990). The fifth discipline: The art and practice of the learning organization (1st ed.). New York: Doubleday.

Senge, P. M. (2000). Schools that learn: A fifth discipline fieldbook for educators, parents, and everyone who cares about education (1st ed.). New York: Doubleday.

Squire, K. D., \& Reigeluth, C. M. (2000). The many faces of systemic change. Educational Horizons, 78(3), 145-154.

Stringfield, S., Ross, S. M., \& Smith, L. (1996). Bold plans for school restructuring: The New American Schools designs. Mahwah, N.J.: Lawrence Erlbaum Associates.

Tyack, D. B., \& Cuban, L. (1995). Tinkering toward utopia: A century of public school reform. Cambridge, Mass.: Harvard University Press.

Watson, S. L., \& Reigeluth, C. M. (2008). Community members' perceptions on social, cultural changes and its implication for educational transformation in a small school district community. Journal of Organisational Transformation and Social Change, 5(1), 45-65. 
Correspondence: Charles M. Reigeluth, Professor, Instructional Systems Technology, School of Education, Indiana University, Bloomington, IN 47405, United States. 